\title{
Movido pelo transcendente: a religiosidade como estímulo ao "espírito empreendedor"
}

\section{Driven by the transcendent: religiosity as a stimulus to the "entrepreneurial spirit"}

\author{
Mauricio C. Serafim ${ }^{1}$ \\ Simone Ghisi Feuerschütte ${ }^{2}$
}

\begin{abstract}
Resumo
Tendo como suporte teórico principal a sociologia clássica weberiana, que debate a relação entre a vida religiosa e o empreendedorismo, e a abordagem schumpeteriana ao empreendedor, este artigo trata da influência da crença religiosa sobre seguidores reconhecidos como empreendedores. A estratégia de pesquisa foi um estudo de caso qualitativo e comparativo sobre empreendedores de duas organizações religiosas: a Igreja Evangélica Renascer em Cristo e a organização católica Movimento dos Focolares. Os dados foram coletados por meio de observação, entrevistas e pesquisa documental. Os resultados indicam que os empreendedores de ambas as organizações preenchem os espaços de incerteza gerados pelas circunstâncias do mercado, por meio da busca pelo "transcendente", o que lhes oferece a segurança subjetiva necessária para a ação. Também foi possível verificar que eles desenvolvem aptidões que não se restringem à mera conduta econômica, dimensão em que suas ações se apresentam como irracionais, porém, alinhadas com o "espírito empreendedor", como a fé e a esperança. Essas aptidões se aproximam do conceito do empreendedor schumpeteriano.
\end{abstract}

Palavras-chave: Empreendedorismo. Organizações religiosas. Comportamento empreendedor. Schumpeter.

\begin{abstract}
Having as its main theoretical support Weber's classical sociology, which debates the relation of religious life to entrepreneurship, and Schumpeter's approach to the entrepreneur, this article addresses the influence of religious belief on followers recognized as entrepreneurs. The research strategy was a qualitative and comparative case study on entrepreneurs from two religious organizations: the Reborn in Christ Evangelical Church and the Catholic organization Focolare Movement. Data were collected through observation, interviews, and documentary research. The results indicate that the entrepreneurs from both organizations fill in the gaps of uncertainty generated by market circumstances, by searching for the "transcendent", which offers them the subjective safety needed for action. It was also possible to find out that they develop skills that are not restricted to mere economic behavior, a dimension in which their actions are shown as irrational, but in line with the "entrepreneurial spirit", such as faith and hope. These skills come close to Schumpeter's concept of entrepreneur.
\end{abstract}

Keywords: Entrepreneurship. Religious organizations. Entrepreneurial behavior. Schumpeter.

Artigo submetido em 12 de junho de 2013 e aceito para publicação em 26 de fevereiro de 2014.

DOI: http://dx.doi.org/10.1590/1679-39519058

1 Doutor em Administração pela Fundação Getulio Vargas/EAESP; Professor e pesquisador do Programa de Pós-Graduação em Administração e do Departamento de Administração Pública UDESC/ESAG. Endereço: UDESC/ESAG, Av. Madre Benvenuta, 2037, Itacorubi, CEP 88035-001, Florianópolis - SC, Brasil. E-mail: serafim.esag@gmail.com

2 Doutora em Engenharia de Produção pela UFSC; Professora e pesquisadora do Programa de Pós-Graduação em Administração e do Departamento de Administração Pública UDESC/ESAG. Endereço: UDESC/ESAG, Av. Madre Benvenuta, 2037, Itacorubi, CEP 88035-001, Florianópolis - SC, Brasil. E-mail: simone.ghisi@udesc.br 
Introdução

Uma ética ancorada na religião destina para o comportamento por ela suscitado prêmios psicológicos (não de caráter econômico) bem específicos altamente eficazes enquanto a fé religiosa permanecer viva [...]. Só na medida em que esses prêmios funcionam e, sobretudo, quando agem (e o decisivo é isto) numa direção que se afasta bastante da doutrina dos teólogos [...], consegue a fé religiosa uma influência autônoma sobre a conduta da vida e, através dela, sobre a economia [...]. (WEBER, 2004, p. 178-179, grifo do autor)

Em determinadas áreas do conhecimento, em trabalhos acadêmicos e na mídia, tem sido recorrente o debate acerca da aproximação das organizações religiosas, em termos de sua estrutura, estratégia e formas de gestão, às empresas contemporâneas com atuação no mercado (SIEPIERSKI, 2001; 2003; MESQUITA, 2003; GONÇALVES, SERRA e COSTA, 2007). O crescimento das práticas empresariais no contexto religioso se evidencia, por exemplo, em muitas igrejas evangélicas e, mais recentemente, na Igreja Católica (SERAFIM, MARTES e RODRIGUEZ, 2012).

Um dos argumentos que justificam essa constatação encontra-se na expansão da lógica econômica - ou racionalidade instrumental - para outras esferas da vida, incluindo a religiosa. Os trabalhos de Berger (2004) mostram que realmente há uma adaptação das igrejas à lógica mercantil, com a adoção de estratégias de comunicação, marketing e com a sistematização de seus processos organizacionais. Nesse sentido, pode-se pensar que a esfera religiosa não é meramente adaptativa, mas capaz de influenciar o comportamento econômico ao oferecer visões de mundo e recursos aos adeptos que se ocupam com a atividade empreendedora.

Ao observar a interseção entre as práticas religiosas e a dinâmica de mercado, é possível constatar a recuperação da tese weberiana de que os valores sociais conformam ações e afetam processos econômicos. Weber (2004) procurou mostrar como o ascetismo religioso contribuiu para aumentar a racionalidade da conduta humana e como influenciou a expansão do capitalismo. Esse sistema, para Max Weber, apoia-se, sobretudo, na organização racional de empreendimentos econômicos, caracterizados por empresas de investimento de longo prazo, pela oferta voluntária de mão de obra, divisão planejada do trabalho, produção baseada na economia de mercado e criação de uma contabilidade racional.

Este artigo aponta "afinidades eletivas" com a tese weberiana e propõe analisar a influência que a crença religiosa exerce sobre os seguidores reconhecidos como empreendedores, bem como verificar que tipo de empreendedor é valorizado nas organizações religiosas. Acredita-se - e configura-se como um pressuposto verificado no estudo - que as organizações religiosas fomentam, simultaneamente, a racionalidade da ação e elementos irracionais - do ponto de vista da racionalidade instrumental - na conduta de seus empreendedores, o que os aproxima do conceito schumpeteriano de empreendedorismo.

\section{Empreendedorismo e Religião}

O tema "empreendedorismo e vida religiosa" remonta à sociologia clássica e tem nos trabalhos de Weber (2004) referência obrigatória. O autor foi um dos primeiros a discutir tal tema e abordar os empreendedores sob a ótica da sociologia, identificando a contribuição do sistema de valores do protestantismo ascético para o éthos empreendedor. Ele distingue o empreendedor capitalista de seu predecessor histórico das sociedades tradicionais por sua busca racional e metódica por ganhos econômicos, pela dependência dos resultados medidos em relação a esses critérios econômicos, pela ampliação da confiança por meio do crédito e subordinação do consumo aos interesses da acumulação. São esses os elementos da racionalidade instrumental do ator econômico racional, por meio do qual estabelece uma relação sistemática de adequação entre meios e fins (SERAFIM e MARTES, 2007). 
A investigação de Weber (2004) focalizou a tensão entre a ética religiosa e a vida econômica, que residia no contraste ou afinidade entre a racionalidade orientada a valores e a racionalidade instrumental moderna. Essa relação tem sido investigada, desde então, sob vários ângulos e em várias áreas das ciências sociais. Ao mesmo tempo, mas não de forma articulada, o conceito de empreendedor/empreendedorismo também é estudado sob diferentes enfoques, tornando necessária uma breve digressão inicial. A influência das áreas do conhecimento que tratam do tema, como a econômica, sociológica e psicológica, justificam as diferentes interpretações sobre o empreendedorismo.

O termo empreendedor começou a ser utilizado apenas no século XVIII, sob a perspectiva econômica, referindo-se aos atores que introduziam em suas terras novas técnicas de agricultura ou arriscavam seu próprio capital na indústria. Os primeiros esforços teóricos de interpretação da função específica do empreendedor foram elaborados por Richard Cantillon (1680-1734), cuja contribuição foi enfatizar a característica de disposição ao risco e à incerteza inerente à atividade empreendedora (HISRICH e PETERS, 2004). Ele observou as atividades de comerciantes e fazendeiros, que negociavam seus produtos a preços de compra e venda instáveis e incertos, submetendo-se ao risco. Jean-Baptiste Say (1767-1832), outro precursor dos estudos sobre o fenômeno, foi quem diferenciou conceitualmente a função empreendedora da função do capitalista e associou os empreendedores à inovação, ao considerá-los agentes de mudança (FILION, 1999). Para Jean-Baptiste Say, os novos empreendimentos é que possibilitariam o desenvolvimento econômico de uma nação. Do mesmo modo que Richard Cantillon, o referido autor reconhecia o empreendedor como o sujeito que, em função de qualidades pessoais típicas expressas em um comportamento inovador, buscava oportunidades que resultariam em lucro, mesmo sob o risco e a incerteza (CARLTON, HOFER e MEEKS, 1998).

Embora Cantillon e Say tenham originado as discussões sobre o empreendedorismo, foi Joseph A. Schumpeter (1883-1950) quem, efetivamente, sistematizou o início desse campo de estudo como próprio da economia. Segundo Schumpeter (1961), o empreendedor é, tipicamente, o agente que, ao promover novas combinações dos fatores de produção, promove desenvolvimento econômico. Para tanto, é primordial o crédito provido pela categoria econômica denominada "capitalista" e materializado na figura do banqueiro. Tendo a inovação como valor, a ação típica do empreendedor não segue a lógica da racionalidade econômica instrumental, voltada para a satisfação de suas necessidades e maximização de utilidade (MARTES, 2010). O desejo de constituição de um "reino privado", a "vontade de conquistar", a satisfação de criar, desenvolver e realizar inovações confere significado específico à ação do empreendedor.

O surgimento das grandes corporações, a expansão do estado de bem-estar social e o crescente aumento da burocratização, processos intensificados nos anos 1950, contribuíram para o declínio de atividades empreendedoras e, em razão disso, o campo passou a ser menos interessante para a pesquisa acadêmica: a função do empreendedor foi sendo substituída pelo quadro técnico das grandes empresas; a intuição, a capacidade de perceber oportunidades, a vontade e a força para levá-las adiante foi sendo assumida por equipes de especialistas e pela prática do planejamento estratégico. Por fim, o indivíduo inovador foi substituído pelo departamento de pesquisa e desenvolvimento (LÓPEZ-RUIZ, 2004). Solidificou-se, então, a "sociedade de empregados" (MILLS, 1969), cujo ator não era mais o empreendedor, mas o que Whyte Jr. (1956) denominou de "homem-organização": indivíduos de uma nova classe média que confundem seus objetivos pessoais com os objetivos organizacionais para os quais trabalham.

A importância do empreendedorismo ressurge nos anos 1980 e, desde então, apresenta-se como processo alternativo à opção por "fazer carreira". As transformações econômicas, como a reestruturação produtiva derivada da internacionalização e institucionalização de novos padrões de concorrência, a precarização e a redução dos postos de trabalho e a mobilização dos profissionais em busca de novos espaços para exposição de seus talentos, aliada às oportunidades surgidas com o fenômeno da globalização e do mercado de trabalho virtual, são alguns dos fatores que estimularam o crescimento do empreendedorismo nas últimas décadas. Nesse novo contexto, o próprio conceito de empreendedorismo foi revisto e vários autores passaram a associar empreendedorismo à criação de novas organizações (THORNTON, 1999; ALDRICH, 2005). É sob essa perspectiva que o conceito de empreendedorismo é reconhecido neste artigo: como um fenômeno que se 
materializa na abertura ou desenvolvimento de um negócio próprio ou no autoemprego, sendo o "indivíduo empreendedor" seu agente.

Voltando-se à religião, ela é considerada, neste trabalho, não um conjunto de ideias concernentes ao sobrenatural ou à transcendência, mas uma prática social, "religião vivida" ou "religião como prática" (SERAFIM, MARTES e RODRIGUEZ, 2012). Dito de outro modo, estudar religião significa adentrar um intrincado conjunto de práticas entrelaçadas com a vida cotidiana e, portanto, com as esferas do trabalho, do consumo e dos negócios (WUTHNOW, 2005; SERAFIM, MARTES e RODRIGUEZ, 2012). Em consequência, há que se pensar na existência de uma clara dimensão econômica na vida religiosa, ou seja, o comportamento econômico socialmente imerso (GRANOVETTER, 2007) também está imerso nas práticas e relações religiosas (WUTHNOW, 2005).

A prática religiosa, analisada sob um ponto de vista econômico, pode ser associada à ideia de ação empreendedora, também incorporada aos estudos do empreendedorismo. Pode-se focalizar três abordagens principais sobre o fenômeno - o contexto, o ator e a ação -, ressaltando a necessidade de percebê-lo em termos da prática do sujeito empreendedor, de sua realização dentro de padrões normativos que o levam a obter sucesso (DANJOU, 2002). As delimitações institucionais orientam a ação empreendedora, que precisa ser analisada por meio das práticas concretas de seu protagonista. Assim, reforça-se a ideia de que não é possível separar a pessoa do empreendedor de seu contexto, de suas relações cotidianas e dos recursos de que dispõe para atingir os propósitos a realizar.

Considerando tal imbricação/imersão, pressupõe-se que a orientação da ação empreendedora também é influenciada, por um lado, pelas relações interpessoais, que podem propiciar recursos econômicos, sociais e informacionais; e, por outro, por aspectos culturais, como a aprovação do grupo a determinadas atividades econômicas, a aceitação de valores e princípios comunitários, como os de origem religiosa. Assim, mais do que pesquisar as formas pelas quais os valores religiosos - ou a ética religiosa - dão limites à racionalidade econômica, a abordagem utilizada busca compreender a atividade empreendedora por meio da estrutura social instituída e delimitada pela igreja enquanto organização, da cultura religiosa (valores, ética) e da orientação doutrinária/teológica. Dessa forma, a doutrina religiosa dá sentido e motivação à ação empreendedora.

\section{Procedimentos Metodológicos}

A pesquisa foi desenvolvida sob a forma de um estudo de caso qualitativo, no qual se analisou e interpretou, comparativamente, a ação de empreendedores ligados a duas organizações religiosas: a Igreja Renascer em Cristo e a Igreja Católica. A escolha desse desenho de pesquisa é consoante com a tendência indicada por Wuthnow (2005), para quem os recentes trabalhos acadêmicos que analisam a relação entre vida econômica e religião são predominantemente qualitativos e utilizam elementos característicos da pesquisa etnográfica. A etnografia se baseia na interação entre o pesquisador e o sujeito pesquisado, deixando de ser uma técnica de pesquisa para oferecer caminhos que possibilitem a melhor compreensão da complexidade dos fenômenos sociais (ANDION e SERVA, 2006). Nesse sentido, a análise da ação de empreendedores religiosos sob uma abordagem etnográfica permitiu conhecer e relacionar aspectos de sua cultura e de sua história, bem como a forma como estas se vinculam a seu contexto de atuação. Por outro lado, a estratégia de estudo de caso foi entendida como um processo que permitiu, sob o enfoque qualitativo, a descrição e a análise de um fenômeno em seu deslocamento por um período de tempo (MERRIAM, 1998). Trata-se de uma escolha metodológica que guarda coerência e alinha-se ao objeto investigado - o empreendedorismo e a religião que não pode ser estudado isoladamente, de forma estática ou desvinculado de seu contexto (YIN, 1984).

O estudo abrangeu a organização pertencente à Igreja Católica, o Movimento dos Focolares, e a Igreja Evangélica Renascer em Cristo, além das respectivas iniciativas de apoio aos empreendedores vinculados a 
tais organizações religiosas. Para desenvolvê-lo, a coleta de dados ocorreu por meio da aplicação das técnicas de observação não participante, entrevistas em profundidade e análise documental.

A observação não participante consistiu de visitas às organizações religiosas mencionadas e às associações empresariais, de participação em cultos e encontros de empresários e de conversas informais com participantes dos eventos e entidades das organizações religiosas envolvidas. A entrevista em profundidade foi realizada com religiosos e leigos católicos, bispos e religiosos evangélicos e empresários de ambas as igrejas, compreendendo um total de 17 pessoas. A técnica de análise documental abrangeu o levantamento e o estudo de artigos e reportagens em jornais e revistas, folders, sites, material publicitário e fotografias relacionadas ao fenômeno em estudo.

Para a análise dos dados, buscou-se comparar a realidade dos sujeitos empreendedores vinculados às organizações estudadas, a partir dos relatos obtidos e da análise e interpretação sobre sua prática. Dessa forma, procedeu-se à triangulação dos dados por meio do uso de recursos e técnicas comuns à pesquisa qualitativa, como categorização, análise de discurso e análise documental.

\section{Resultados da Pesquisa: Apresentação e Análise dos Casos}

Neste tópico, busca-se descrever aspectos das organizações religiosas abordadas na pesquisa, bem como de seus empreendedores, com destaque para seu envolvimento com as práticas das igrejas nas quais atuam, visando a compreender a influência dessas organizações sobre sua ação empreendedora.

\section{A Igreja Renascer em Cristo e o vínculo com a atividade empresarial}

A Igreja Evangélica Apostólica Renascer em Cristo (IRC) foi fundada em 1986, na cidade de São Paulo, por Estevam Hernandes, ex-gerente de marketing das empresas Xerox e Itautec. A IRC insere-se na linha neopentecostal que, no plano teológico, se caracteriza pela ênfase na "guerra espiritual", na teologia da prosperidade, rejeitando usos e costumes de santidade pentecostal e tradicionais símbolos de conversão. Como característica doutrinária distintiva da IRC encontra-se a ênfase na "restauração", ou seja, no restabelecimento da harmonia, em todas as dimensões, das pessoas marcadas por experiências negativas (SIEPIERSKI, 2001).

A maioria dos fiéis seguidores da IRC tem perfil jovem e é oriunda de classe média baixa, porém, nas duas últimas décadas, um importante segmento de empresários e profissionais autônomos passou a frequentar a igreja. A IRC passou a valorizar mais a adesão de empresários do que a dos jovens tendo, inclusive, em 1996, fundado a Associação Renascer de Empresários e Profissionais Evangélicos (Arepe), que visa a aproximar e apoiar profissionais autônomos, pequenos e médios empresários e aqueles que almejam iniciar um negócio próprio (SIEPIERSKI, 2001).

As demais linhas de atuação da IRC concentram-se na Fundação Renascer, que funciona como uma espécie de holding que controla a igreja e as diversas organizações ligadas a ela. A Fundação Renascer mantém inúmeros projetos assistenciais, tais como, a Casa Lar (residência para crianças abandonadas), a Casa Calebe (residências para idosos) e os centros de recuperação para dependentes químicos. Além disso, administra a gravadora musical Gospel Records e a distribuidora Point Gospel Renascer; várias emissoras de rádio lideradas pela Gospel FM de São Paulo; a Rede Gospel de Televisão; um estabelecimento de ensino privado (denominado de Esar); um portal que oferece cursos à distância - do Ensino Fundamental a cursos de especialização (denominado Unir); a Orquestra Apostólica Renascer em Cristo; o grupo musical Renascer Praise, liderado pela Bispa Sônia (com shows gravados ao vivo no estádio do Ibirapuera); e a Marcha para Jesus, passeata que ocorre anualmente na cidade de São Paulo, atraindo milhares de pessoas de diferentes religiões, e acompanhada de trios elétricos que tocam músicas gospel. Em termos de suas práticas de gestão, a Igreja Renascer em Cristo se alinha a modelos empresariais, destacando-se o uso intensivo dos meios de 
comunicação - principalmente os eletrônicos - e a ênfase na arrecadação de dinheiro dos fiéis por meio de dízimos, ofertas nos cultos e doações.

\section{O empreendedor apostólico: suas crenças e ações}

Para conhecer a influência que a crença religiosa da IRC exerce sobre seus seguidores tidos como empreendedores, buscou-se desvendar a visão que a própria igreja e seus fiéis têm a respeito do mundo dos negócios que cerca os empresários e os profissionais que a frequentam. A partir das entrevistas realizadas com nove seguidores da IRC, foi possível perceber valores e princípios que vinculam a religião à esfera econômica.

O desdobramento do discurso dos representantes da IRC no campo profissional é a crença de que ser bemsucedido nos negócios requer não apenas a competência profissional e a racionalidade administrativa, mas algo que é um bem essencial: a bênção de Deus. Para obtê-la, é imprescindível que as ofertas sejam feitas a Ele, sendo a igreja a intermediária do processo. Dito de outra forma, o sucesso e o lucro ou, em termos gerais, a boa performance empresarial, são considerados efeitos da performance espiritual, que permite a intervenção do poder sobrenatural de Deus.

É pressuposto, no contexto analisado, que o mundo espiritual determina o mundo material. Portanto, antes de tudo, os homens devem ser "guerreiros espirituais" para que a dádiva divina seja desbloqueada pelas entidades demoníacas. Para tanto, utilizam os rituais e praticam atividades religiosas, como jejum, orações, participações nos cultos e ofertas, adicionalmente à consagração dos instrumentos ou local de trabalho. Nesse sentido, destaca-se que "é através da participação das práticas rituais da Igreja que o fiel passa a 'ter Jesus como sócio' e é marcado para o sucesso financeiro" (MESQUITA, 2003, p. 100). Essas ações realizadas pelos indivíduos são, portanto, vistas como uma estratégia, como bem afirmou um dos entrevistados: "Tudo é estratégia, porque se está numa guerra".

Para os entrevistados vinculados à IRC, o mundo é corrompido e decaído, e o mercado ${ }^{3}$ é um reflexo deste mundo, devendo-se considerar a realidade "como ela ê" - com sua lógica e racionalidade econômica - e não tentar modificá-la, ou ainda, melhorá-la em busca de justiça social. Ressaltam, todavia, que se o mercado é corrompido e corrupto, o empreendedor deve nele agir sem se corromper. Para isso, ter a Bíblia como orientadora de suas ações é fundamental, pois ela é, de acordo com um dos entrevistados, "a boca de Deus".

Conforme os relatos obtidos, observou-se a visão de que a Bíblia é atual na maneira como orienta os negócios, precisando apenas de algumas adaptações, tarefa que cabe à igreja. Um dos entrevistados utilizou dois exemplos do Antigo Testamento para mostrar a capacidade da Bíblia de dar conta, inclusive, do mundo dos negócios. O primeiro exemplo foi do livro do Gênesis (2, 19-20), no qual é possível interpretar que Deus criou Adão também como um administrador, e que ele, Adão, possuía tamanha capacidade de gestão que conseguiu nomear todos os animais e seres animados do mundo. Já o segundo exemplo foi que Davi, eleito por Deus para ser rei, pode ser considerado um empresário e, como tal, foi um grande empreendedor ao ampliar imensamente seu reino, tornando-se muito rico e bem-sucedido nos negócios.

Para esse tipo de empreendedor, que se pauta na doutrina da igreja como fonte de prosperidade, há um termo específico na IRC: "empreendedor" ou "empresário apostólico". A conduta do empresário apostólico deve ter como propósito suprir sua família e a igreja; ser empreendedor, ou seja, aquele que "faz tudo para ser bem-sucedido", de acordo com a doutrina; e conquistar bens materiais: "ter" é uma consequência de "ser" servo, ter bênção, "limpo" nas intenções. No mesmo sentido, um dos entrevistados definiu o empresário apostólico como "aquele que não tem medo do desafio, enfrenta todas as dificuldades com muita coragem". $\mathrm{Ou}$, ainda, "é aquele que persevera, segura, vai para frente, é ousado, agressivo (no bom sentido), agarra

\footnotetext{
3 "Mercado" é a expressão utilizada pelos entrevistados.
} 
as oportunidades, não é acomodado, é um 'empreendedor'. Não se conforma com o presente, é um 'inconformado'”.

Em referência a essas interpretações, o termo "empreendedor" é observado sistematicamente nas práticas da IRC, tanto nos cultos da Arepe como nas palestras e nos seminários. Ser empreendedor significa "pôr-se em ação" no campo empresarial, fazer algo que está além do comum entre os empresários. Como na afirmação do entrevistado, o empresário apostólico não é mero empresário, ele é um empreendedor. Ou melhor, não é mero empreendedor, é um empreendedor que conta com a propriedade sobrenatural da fé. Trata-se de um empreendedor que sacraliza o cotidiano.

O discurso dos sujeitos da pesquisa revelou ser a "fé" uma propriedade singular e muito valorizada pela IRC e pelos empreendedores. Um dos entrevistados afirmou que já ocorreram fatos reconhecidos por ele como "milagres", como o pagamento de dívidas de clientes inadimplentes há muito tempo em momentos nos quais necessitava sobremaneira ser ressarcido. Outro relatou que havia "perdido tudo" após oito meses de seu batizado na IRC porque continuava a "viver no pecado" e, por isso, "o diabo atuou em sua vida". Após a retomada de sua fé a empresa começou a obter melhores resultados com significativo crescimento no período de um ano - como o aumento de 19 para 50 funcionários. Esse empresário atribui a mudança da situação aos votos feitos a Deus, ao pagamento do carnê do Gideão e às ofertas realizadas. Para ele, ocorrem fatos sobrenaturais nos negócios: "Se você chega como servo de Deus [em um cliente], você fecha o negócio"; nos negócios, "o Espírito Santo fala com você". De acordo com o entrevistado, a atuação do Espírito Santo ocorre ao se pedir discernimento, por meio da oração do fiel empreendedor, para que seja feita a vontade de Deus naquele momento, porque como "Deus não gosta que a gente retroceda", Ele "[...] não te coloca em projetos furados". E complementa: "Quando se está no caminho de Deus, se consegue tudo".

Em relação a esses empreendedores que atribuem os bons resultados de seus negócios ao "mover sobrenatural", ressalta-se que

[...] a compreensão das circunstâncias do mercado que não lhes proporciona as condições necessárias para a solução de seus problemas é mediada pela busca do transcendente [...] que pode auxiliá-los mediante as incertezas da vida e dar-lhes a segurança de que necessitam (MESQUITA, 2003, p. 137).

Esse mecanismo parece ser tão eficiente que os entrevistados mostraram sempre muita confiança em si e no mundo espiritual. Alguns afirmaram, inclusive, que antes de preocupar-se com o mercado (como a desvalorização do dólar, por exemplo), preocupam-se primeiro com a vontade de Deus, porque, para um fiel, ser bem-sucedido no primeiro é consequência do discernimento do segundo; ou, como um dos entrevistados enfatizou, "a estratégia é espiritual e tem consequências no material". Essa fé é traduzida no proferimento constante da expressão "milagre não se explica, se vive", geralmente acompanhada de relatos como: “[...] não sei como consegui as coisas, não tenho capacidade para tudo o que tenho".

Em termos mais gerais, é possível sugerir que a fé na atuação divina se traduz em expectativas positivas e otimistas, ensinando aos empreendedores a convivência com o risco de suas ações empresariais, ou seja, a conviver com o que não pode ser resolvido imediatamente - ou talvez nunca -, sem se deixar angustiar pelas incertezas, pois uma "pessoa de fé" não se deixa abalar facilmente.

Além disso, compreende-se que nessa perspectiva as dificuldades são consideradas coadjuvantes do sucesso, porque, segundo um dos entrevistados, "quanto maior o desafio, maior o peso da vitória", e a perseverança é o elemento-chave para esse sucesso. Isso significa que eles devem traçar objetivos bem claros, sem se preocupar demasiadamente em como esses objetivos serão atingidos, porque terão a "bênção liberada" caso tenham fé e consagrem a oferta (MESQUITA, 2003).

Diante dessa interpretação, talvez se possa afirmar que há um elemento irracional na ação econômica do empreendedor (SWEDBERG, 2005): a esperança - sem as bases racionais que articulam meios e fins - de 
que "tudo vai dar certo" devido à ação divina, e a crença de que, provavelmente, não se conseguiria atingir os objetivos de outra forma. As dificuldades, os riscos e as incertezas são todos subjetivamente amenizados pela certeza de que "vencerá, em nome de Jesus" e não tanto pelo controle, planejamento, metodização e previsibilidade da racionalidade econômica.

É interessante notar que há uma orientação valorativa baseada na racionalidade substantiva (WEBER, 1999; RAMOS, 1989), a qual, entretanto, não é exclusiva porque a ação desses empreendedores visa não apenas ao cumprimento de um dever em si, mas ao alcance de objetivos que lhes são muito claros. Dessa forma, não há tensão alguma entre essas duas racionalidades, ambas se complementam.

Ao analisar o perfil dos empreendedores pesquisados na IRC, dois padrões de biografia pessoal e de empresa chamam a atenção e estão relacionados ao "antes e depois" de entrar para a igreja. O primeiro padrão referese aos problemas pelos quais os empreendedores passavam, como dependência de drogas, distúrbios psiquiátricos, angústias existenciais (falta de sentido da vida) e dificuldades econômicas (expressas na frase "havia perdido tudo").

Segundo seus depoimentos, ao realizar a experiência da conversão - pela qual todos os entrevistados passaram - conquistaram a "libertação de seus vícios e de seus pecados", fontes de sua condição, e adquiriram um "novo estilo de vida, uma nova concepção de mundo, de eu, de liberdade, enfim uma nova episteme [...]" (MARIZ, 1994, p. 218). Isso é sintetizado na frase de um dos entrevistados: "Jesus me tirou do pó".

A "conversão possibilita a reinterpretação da biografia, das experiências anteriores, fomentando a transformação e a redefinição da identidade, tanto na vida secular quanto na religiosa" (MESQUITA, 2003, p. 106). Nesse aspecto, todos os entrevistados consideram a conversão o marco zero da retomada de suas vidas e do desenvolvimento positivo de seus negócios, tal como ilustra este depoimento: "[...] era drogado, estava falido e Deus restaurou".

O segundo padrão, relacionado ao anterior, é a afirmação de que as "coisas boas" foram obtidas após a conversão e de acordo com o comprometimento com os rituais e as ofertas. Alguns entrevistados destacaram que, atualmente, são menos ricos em termos financeiros do que antes de entrar na igreja; porém, são mais ricos em todas as outras dimensões de suas vidas.

Como revelado nos depoimentos, os empreendedores se tornam bastante comprometidos com as atividades da igreja, participando de seus programas assistenciais e dos ministérios de diferentes formas. Além da contribuição financeira e do consumo de bens e serviços de empresas vinculadas à Fundação Renascer, é comum os empreendedores se dedicarem por dois ou mais períodos na semana às atividades assistenciais da igreja. Além disso, também realizam cursos no Centro de Estudos Renascer, visando ao aprimoramento da doutrina e das práticas eclesiais. É comum, ainda, os empresários se integrarem como membros da estrutura eclesial da igreja, tornando-se diáconos, presbíteros e bispos.

Atuando voluntariamente ou inserindo-se na estrutura eclesial da igreja, os empreendedores também desenvolvem entre si uma forma de solidariedade. Há casos de empresários que, por atuar nos mesmos grupos de ação assistencial, estreitaram seus laços e passaram a trocar conhecimentos não apenas religiosos, mas técnicos. Pelo que foi possível apreender, a troca de conhecimentos técnicos se circunscreve às experiências e orientações mútuas sobre os negócios. Alguns dos entrevistados afirmam que fazem orações juntos e, esporadicamente, prestam pequenos serviços religiosos uns aos outros, como no caso em que um deles foi abençoar a empresa de outro empreendedor, aplicando "óleo ungido" a seu redor.

Com base nos relatos e nas percepções obtidas dos empreendedores apostólicos, verificou-se que sua relação com a IRC se sustenta por meio da realização de trabalho voluntário, oferta de dízimo e de outros recursos, além do desenvolvimento de sua educação religiosa em cursos e da ajuda oferecida informalmente entre os empreendedores, devido à convivência nos mesmos projetos e ações. Quanto à vinculação de sua prática religiosa com a atividade empresarial, observou-se a atribuição aos desígnios divinos do sucesso ou 
insucesso e da falta de prosperidade nos negócios. Tal crença se expressa na forma como os empreendedores associam sua fé à organização religiosa, ou seja, à medida que creditam seu insucesso empresarial à falta de aproximação com Deus, mais se dedicam a ofertar e trabalhar com - e para - a igreja. Paradoxalmente, ao lado dessa vinculação pela fé se estabelece a racionalidade instrumental, que orienta a ação dos empreendedores na direção de seus objetivos materiais, definidos no mundo concreto dos negócios.

\section{A Igreja Católica e o Movimento dos Focolares: espiritualidade e empreendedorismo}

O Movimento dos Focolares (MF) é um movimento eclesial e civil da Igreja Católica, iniciado por Chiara Lubich (1920-2008), em 1943, na Itália. Atualmente, o MF é difundido em 194 países, com a participação de 180 mil membros internos e em torno de 2 milhões de aderentes e simpatizantes (MOVIMENTO, 2014). No Brasil, o movimento teve início em 1959, em Recife-PE, com a chegada da Itália de Ginetta Calliari (19182001) junto com outras 3 focolarinas e 4 focolarinos. O MF e seus representantes estão presentes na maioria das capitais brasileiras e em algumas cidades do interior.

A característica principal do MF é a espiritualidade da unidade, com o compromisso estabelecido entre seus membros de viver o "mandamento do amor recíproco". Esses dois elementos constituem o que o MF chama de "paradigma da unidade", que significa a vivência do amor recíproco de modo a construir a unidade: com pessoas e povos; com outras denominações religiosas; e na própria Igreja Católica. Sob essa perspectiva, o objetivo oficial do MF é "contribuir para compor em fraternidade a família humana" (MOVIMENTO, 2014).

Em termos de estrutura organizacional, o MF contou com Chiara Lubich na presidência - até sua morte, em março de 2008 - dirigindo o movimento auxiliada por um copresidente e um conselho. Fazem parte da estrutura formal, ainda, os focolares - pequena comunidade formada por homens ou por mulheres (separadamente), de 4 a 5 membros; são os leigos consagrados que fazem os votos de pobreza, castidade e obediência e são chamados focolarinos e focolarinas. Esses membros geralmente moram em uma casa que serve como local de encontros e de referência aos participantes do movimento. Também integram a estrutura do movimento os focolarinos casados, que moram com suas famílias, e as mariápolis permanentes, que são pequenas comunidades onde famílias, jovens, padres e religiosos moram e trabalham de forma compartilhada. Esses grupos comunitários constituem centros de formação social e religiosa do MF, nos quais são formados os novos focolarinos. Os centros mariápolis são locais de encontros (como conferências, congressos, palestras) para os membros e simpatizantes do MF.

Uma das atividades do MF no campo econômico é denominada "economia de comunhão" (EdC). Proposta por Chiara Lubich, a EdC teve início no Brasil em 1991 e tem por objetivo principal a "transformação cultural da vida econômica e empresarial", sob a doutrina do "paradigma da unidade". Um dos propósitos da EdC em seus projetos e práticas é disponibilizar parte dos lucros das empresas às pessoas mais pobres, suprindo necessidades básicas como alimentação, vestuário, higiene, assistência médica, educação básica e habitação, ou disponibilizando postos de trabalho.

A atividade mais significativa promovida pela EdC no Brasil é o Polo Empresarial Spartaco, localizado no município de Cotia-SP. Criado em 1994 e ligado à Mariápolis Permanente Ginetta, o polo busca "[...] dar viabilidade e visibilidade ao projeto $\mathrm{EdC}$, proporcionando às empresas um local apropriado para se instalar e colocar em ação, como em um laboratório, essa nova experiência econômica" (LADAIN, COSTA e SALLES, 2012). Em 2012, 99 funcionários diretos e 50 funcionários indiretos trabalhavam no Polo Empresarial Spartaco, distribuídos nas seguintes empresas: Espri S. A. (Empreendimentos, Serviços e Projetos Industriais), Ecoar (produtos de limpeza), KNE-Rotogine (rotomoldagem de plásticos), Uniben Fomento Mercantil Ltda. (factoring e seguros), Prodiet Nutrição Clínica (distribuidora de medicamentos), AVN Embalagens (embalagens plásticas), além da Associação dos Funcionários do Polo Spartaco (LADAIN, COSTA e SALLES, 2012).

Essas empresas se organizam em regime de condomínio administrado pela holding Espri S.A., que provê suporte estrutural e de gestão ao polo. A Espri canaliza recursos para as empresas sob a forma de 
participações feitas por intermédio de subscrição de cotas de capital, cuja propriedade é conservada pelos participantes (atualmente cerca de 3.900 acionistas), mesmo sem ter expectativas de lucro em um prazo definido.

\section{O Empreendedor Católico: suas crenças e ações}

O desdobramento do discurso e das práticas do MF no campo empresarial foi institucionalizado no projeto Economia de Comunhão (EdC), que atua no campo econômico e é conduzido pelo Movimento Humanidade Nova, expressão no campo social do MF. Nesse movimento, a ética do trabalho é congruente com o discurso oficial da Igreja Católica, enfatizando elementos gerados da espiritualidade da unidade, como o amor evangélico e a pobreza escolhida, a ser abordados a seguir.

Sob a perspectiva do MF, os negócios são bem-sucedidos quando sustentados na competência profissional e na racionalidade econômica. Aliado a esses requisitos são necessários outros juízos racionais, não econômicos, para que se alcance sucesso nos negócios. Como a EdC é considerada pelos membros um projeto de Deus conduzido pelos homens por meio do MF, são inseridos no campo econômico critérios advindos da esfera religiosa e que dão um caráter diferente à ideia de ser bem-sucedido.

Para um desses empreendedores da $\mathrm{EdC}$ - definido por um dos entrevistados como "alguém que põe seus talentos a serviço dos irmãos, para melhorar sua condição material, mas, sobretudo, para promover a fraternidade no mundo" - mais importante que os resultados financeiros é a maneira como o processo de gestão é conduzido em direção aos objetivos da EdC. "Trabalhar, não para produzir lucros, mas produzir lucros para construir uma nova cultura", como afirmou um dos empreendedores entrevistados, é um bom resumo dessa visão de mundo.

O objetivo empresarial sob tal perspectiva possui uma conotação transcendente, qual seja, a de construir a nova cultura, a "cultura do dar", expressão muito utilizada entre os membros. De modo mais amplo, o propósito é contribuir para a construção do "paraíso terrestre", que se materializa na ajuda aos pobres e no estabelecimento de relacionamentos de reciprocidade - amor mútuo. Sobre este último, o "amar a todos" é considerado o meio e o fim da ação empresarial. Para os empreendedores, o amor evangélico é o principal motivador de suas ações sociais, como a ajuda financeira aos pobres cadastrados no MF e o esforço de pagar em dia e integralmente seus impostos (FERNANDES, 2007).

Como ilustração a tal visão, reproduz-se a fala de um empreendedor, descrevendo sua forma de agir, sob a orientação do amor evangélico, diante de uma situação particular na qual assumiu atitude de paridade com seus funcionários:

Nestes dias de feriado de Natal, fizemos o inventário de estoque. Mais de 2.500 itens para ser contados. Isso significa que devíamos ver em cada produto: quantidade, código de barras, lote, vencimento, endereço, marca, fabricante, substância etc. Imagine o trabalho. Trabalhamos dia 22, 23 e 24 até às 12:00. Mais de 80 pessoas envolvidas divididas em várias equipes. De minha parte, foi natural estar envolvido numa destas equipes, fazendo aquilo que todos deviam fazer. Para mim, algo normal, mas para muitos um verdadeiro espanto e motivo de muita alegria. Senti claramente um ambiente leve, porém, de muito trabalho e responsabilidade. Eu não participei por ser exemplo ou cobrar dos outros. Mas porque, na nova cultura da EdC com a qual estou envolvido (do amor no ambiente de trabalho e da gratuidade das nossas ações), diziam-me que deveria estar ali, ao lado de todos, vivendo a realidade que todos vivem [...] É claro que no dia 26 retornarei às minhas atividades que os outros não poderão fazer.

Como se percebe nesse depoimento, o empreendedor se assume como tal não apenas na esfera econômica, mas, também, na esfera religiosa por meio do projeto da EdC. Nesse projeto, ele é um membro do movimento e, ao mesmo tempo, um empreendedor da EdC. Por isso, assume algumas responsabilidades, 
como dar seu testemunho como empresário, tentar aplicar na ação gerencial os princípios do movimento e receber os pedidos de estudantes e pesquisadores que os procuram para seus trabalhos. Pode-se falar, então, de uma imersão dupla (double embeddedness) do empreendedor: ele está simultaneamente imerso no contexto institucional do capitalismo de mercado e no contexto cultural ou na rede de relações sociais religiosas (MARTINELLI, 2004).

Um dos efeitos da imersão nesse contexto cultural é que a conduta dos empreendedores é orientada por fortes convicções religiosas, a ponto de considerar que todas as dimensões da vida são "inundadas" pelo éthos religioso. Em outros termos, "[...] tratar do 'elemento Divino' significa tratar de todos os demais, visto que esse fator perpassa, sustenta, sintetiza e viabiliza tudo o que existe, no real e no imaginário" (PINTO, 2004, p. 307). Isso significa que modelos formais de gestão são adotados pelos empreendedores e coadunados aos princípios da espiritualidade da unidade, em uma tensão constante entre a ética da responsabilidade e da convicção (RAMOS, 1966); ou seja, há um esforço por parte dos empreendedores para equacionar a responsabilidade de manter a empresa competitiva e os valores religiosos com os quais estão comprometidos. Esse esforço se deve à busca da manutenção da coerência da visão de mundo acerca da espiritualidade da unidade, considerada universal e, portanto, não é condizente com o "relativismo ético", que pressupõe a adoção de critérios como certo/errado, justo/injusto, lícito/ilícito, que se modificam de acordo com a situação ou com a esfera em que se encontram (familiar, econômica, religiosa). Nesse sentido, vale ressaltar que essa crença leva, por vezes, a tomadas de decisão econômicas motivadas por razões não econômicas, como ilustra o relato a seguir:

Certa vez, um cliente nos solicitou um pacote turístico para Europa. Custava em torno de US\$ 2.700 para cada pessoa, e como viajaria o casal, o preço seria o dobro. Fizemos as reservas e combinamos tudo com os clientes. Quando fomos fazer o pagamento com a operadora internacional, ela nos informou que aquele pacote tinha entrado em promoção naquela semana e que custaria em torno de $30 \%$ a menos. Como já estava tudo combinado com os passageiros, poderíamos ter ficado com esse desconto para nós, sem repassá-lo ao cliente. Porém, procurando agir com honestidade e a ética nos relacionamentos, repassamos todo o desconto para os clientes, mesmo sabendo que, nesse caso, nossa comissão também seria reduzida.

Ao abordar o vínculo dos empreendedores com o movimento católico do qual fazem parte, observa-se que o sentimento de pertencimento à comunidade dos focolares é tão importante que há uma denominação especial a esse estilo de vida: espiritualidade coletiva. O participante entende que sua atuação como empreendedor da EdC não diz respeito apenas ao âmbito pessoal ou à sua organização econômica, mas ao conjunto da organização religiosa. Esse compromisso com o MF e com o projeto EdC é evidenciado em dois aspectos. Primeiro, um motivo primordial para eles se tornarem empreendedores ou - se já o são - para aderirem ao projeto EdC é "dar uma resposta ao pedido de Chiara", como costumam dizer. Segundo o relato de um deles, "nossa experiência começou com um grupo de amigos que, entusiasmados pela proposta de Chiara sobre a EdC, não puderam ficar parados, de braços cruzados". Sob essa visão, portanto, o "ser empreendedor" não é apenas cumprir uma função, tal como refere Schumpeter (1961), significando também uma vocação ${ }^{4}$ - que exige competências profissional e espiritual - para participar da construção coletiva do que denominam cultura do dar.

O segundo aspecto que os motiva a estar na EdC é o senso de missão e o risco que assumem, conscientemente, em favor de uma ação coletiva. Segundo o relato de um dos empreendedores, "naquela época [1998] todos nós tínhamos nossos próprios empregos, em boas empresas, porém, o amor que nascia em nós pela EdC fazia vislumbrar que, no futuro, todos trabalharíamos juntos [grupo de amigos]". Para outro entrevistado, com tal envolvimento se arrisca também a própria empresa, uma vez que a vivência de

\footnotetext{
${ }^{4}$ De acordo com o Dicionário Houaiss, "vocação" se origina do latim vocatio - onis: "ação de chamar; intimação, convite". Portanto, há uma relação entre o "chamado de Chiara" e a ideia de ser empreendedor como uma vocação.
} 
valores religiosos - que têm consequências éticas na conduta econômica do empreendedor - pode acarretar perdas nos negócio. Esse foi o caso de um empreendedor que relatou que alguns clientes o veem como "não parceiro", porque o modelo de negócio proposto por eles é incompatível com seu padrão ético.

O risco também ocorre ao se procurar contribuir com o projeto instalando suas empresas ou filiais no polo empresarial. Certamente, são feitos cálculos de viabilidade econômica, podendo-se dizer que o risco possui certo grau de cálculo. Porém, como relatou um empreendedor, ele não se instalaria no polo se não fosse pelo projeto da EdC. Os empreendedores arriscam-se, ainda, ao doar parte dos lucros segundo os propósitos da $\mathrm{EdC}$, o que, apesar de ser feito com cautela, diminui o valor que poderia ser reinvestido na empresa ${ }^{5}$.

A abnegação, ou o sacrifício de arriscar-se, é parte do que no MF se denomina "pobreza escolhida". Acredita-se que o empreendedor de EdC deva ser "pobre", ou seja, adotar livremente um estilo de vida sóbrio porque se entende que os bens e as coisas devam ser colocados em circulação, considerando-os como dádivas (BRUNI, 2005). O acúmulo de capital para proveito próprio e o consumismo são desencorajados porque não estimulam a comunhão e, portanto, não levam à cultura do dar.

O estilo de vida com fins religiosos, de acordo com a crença do MF, tem como resultado a atuação do "sócio invisível", termo usado para designar a providência divina. Os empreendedores contam com essa atuação principalmente em momentos de dificuldade. Um dos entrevistados atribui ao sócio invisível acontecimentos como, por exemplo, a geração de negócios imprevistos, o pagamento de uma dívida no momento em que mais precisava e a não efetivação de um negócio que poderia ser nocivo à empresa. Dessa forma, as angústias, os riscos e as incertezas são amenizados subjetivamente pela garantia da atuação do sócio invisível, caso as condições necessárias (amor mútuo, Jesus em meio) estejam presentes.

Em se tratando do perfil dos empreendedores católicos, dois padrões em suas biografias chamam a atenção. O primeiro é que eles não vêm de uma experiência de conversão, mas de continuidade, pois geralmente são membros internos, aderentes ou simpatizantes do MF. Alguns relatam certas mudanças de ênfase em relação a seu trabalho ao se esforçar para transpor o conjunto de princípios, crenças e valores do MF para a prática administrativa. Entretanto, o mais comum é que a adesão à EdC seja entendida mais como uma continuidade daquilo que o empreendedor vivenciava na organização religiosa, com a diferença de que a EdC organizou e categorizou as ações religiosas no campo econômico. O segundo padrão é o histórico de uma inclinação pela busca de justiça social por parte dos empreendedores. Por exemplo, como afirmou um dos entrevistados,

[...] minha atividade empresarial da época [antes de entrar para a EdC] não preenchia meus anseios mais profundos de ajudar na construção de uma nova realidade social a partir da atividade econômica. [...] A EdC e tudo aquilo que ela compreende foi a resposta.

Essa fala ilustra uma ponderação comum entre os empreendedores, de que a EdC "é a resposta" para seus anseios ou, em outros termos, sua fornecedora de sentido, principalmente pelo caráter de grupo ou comunitário do projeto, pela delineação de propósitos claros e pela criação de uma "tecnologia religiosa" (SERAFIM, 2013), da adequação de valores religiosos às ações orientadas economicamente.

Além do projeto EdC, os empreendedores também são bastante empenhados em outras atividades do MF. Para citar algumas, assumem compromissos de organizar eventos, participam de grupos - como o Famílias

\footnotetext{
${ }^{5}$ Uma importante questão a colocar são os motivos que levam os empreendedores que frequentam o MF a não aderir à EdC. Segundo os depoimentos obtidos, alguns desses motivos são: 1) às vezes, um empresário do movimento tem sócios que não estão interessados em se integrar ao movimento e ele não fica livre para aderir como uma empresa; 2) a empresa não alcançou uma solidez ou passa por momentos de crise; 3) Nessa situação anterior, se o empreendedor fizesse parte da EdC, poderia ser um contratestemunho ao movimento, o que faz com que não se sinta digno - pode ser reconhecido como alguém sem capacidade de gerir de forma positiva, de não obter lucro; 4) alguns empreendedores pensam que fazer parte da EdC é dar lucro apenas, mas não é isso: a EdC é "dar a vida"; então, há falta desse entendimento e isso mostra a falta de formação de alguns empresários, o que motivou a criação de escolas de formação.
} 
Novas - encontros de comunidade ${ }^{6}$, encontros de voluntários, encontros de focolarinos casados, além de fazer visitas periódicas aos focolares locais. Esse envolvimento faz com que muitos empresários se relacionem em outros espaços, além dos frequentados em função do projeto de $\mathrm{EdC}$, fortalecendo os laços de solidariedade que, por sua vez, intensificam os vínculos entre os empreendedores no próprio projeto.

\section{O esforço da comparação: aproximando crenças e ações de empreendedores religiosos}

Para melhor compreender a influência da crença religiosa sobre os empreendedores estudados e para aprofundar a visão sobre seu perfil, buscou-se desenvolver uma análise comparativa entre a identidade e o papel atribuído a esses indivíduos, bem como em relação à percepção que têm sobre sua própria condição e a interpretação de suas ações nos movimentos nos quais estão integrados.

Ao se tratar da identidade dos participantes dos dois grupos estudados, ambas as organizações têm uma denominação especial para seus empreendedores-membros: empreendedor apostólico (IRC) e empreendedor da EdC (MF). Há uma crença comum entre eles, segundo a qual a competência profissional e a racionalidade administrativa são elementos necessários, mas não suficientes, para o bom desempenho empresarial. Também há o acréscimo fundamental da propriedade sobrenatural da fé, ou seja, que Deus atua nos negócios. Dessa forma, há uma "mão invisível" não mais "do" mercado, mas "sobre” o mercado.

Em relação ao propósito de suas ações, o empreendedor apostólico busca ser próspero com base na doutrina da IRC. Ele tem a função de suprir a família e a igreja, de conquistar bens materiais e de ser um empreendedor, entendido como "aquele que faz tudo para ser bem-sucedido". Seu sucesso, o lucro e a boa performance empresarial são decorrentes da performance espiritual, significando que não basta adotar estratégias empresariais, pois se deve levar em conta - se não for a mais importante - a estratégia espiritual, que consiste na observação das "leis espirituais" e na transformação do empreendedor em um "guerreiro espiritual", em constante luta contra os "inimigos invisíveis" que insistem em reter sua prosperidade. Para essa estratégia, Jesus deve ser considerado um sócio e a Bíblia o melhor livro para a orientação dos negócios, com as devidas atualizações. Para o empreendedor, há uma relação diretamente proporcional entre a condução moral de acordo com os princípios religiosos e observação de rituais e o fato de ser financeiramente bem-sucedido. Em uma palavra, o "ter" é uma consequência do "ser".

Diferentemente, o empreendedor de EdC procura ajudar a construir a cultura do dar - como é entendida no MF - na esfera econômica. Tem a função de transformar sua empresa em um instrumento de justiça social e, em uma pequena comunidade onde deve estar presente a espiritualidade da unidade, para ser testemunho da veracidade do projeto EdC para que o "mundo creia" (Evangelho segundo São João 17, 21). Para o empreendedor católico, então, ser bem-sucedido nos negócios significa não apenas ter bons indicadores econômicos, mas ser capaz de cumprir os objetivos da EdC, o que inclui seu próprio modo de vida (pobreza escolhida) e o agir de acordo com o éthos focolarino. Em situações de dificuldade, confia na participação do "sócio invisível", que atua na medida em que o empreendedor "faz sua parte", ou seja, cumpre os critérios materiais (dos negócios) e espirituais. Entretanto, o mais importante nessa dinâmica, segundo os entrevistados, é o que denominam de "vontade de Deus". Isso significa que, caso tal dificuldade não consiga ser contornada, pode ser entendida como uma manifestação misteriosa de Deus. Ao sucumbir diante da dificuldade, não seria mero fracasso, mas um "fracasso glorioso", pois a constelação simbólica do MF (SERAFIM, 2013) ressignifica aspectos negativos da vida em geral e dos negócios em particular, o que, em termos práticos, pode ser compreendido como renúncia e desapego. Tudo tem um sentido que, ao final, seria a expressão da vontade de Deus.

\footnotetext{
${ }^{6}$ São reuniões mensais das Palavras de Vida abertas a todos. Palavras de Vida são textos de reflexão espiritual atribuídos a Chiara e os membros são convidados a viver aquele mês conforme a reflexão.

${ }^{7}$ Expressão de Serafim e Martes (2007) que corresponde aos demônios do mundo espiritual. O objetivo é contrastar com a expressão "sócio invisível" criada pelo MF.
} 
De acordo com as manifestações e crenças dos empreendedores pesquisados, tanto para apostólicos como para os de EdC, os espaços de incerteza das circunstâncias do mercado são preenchidos pelo "transcendente", que lhes dá sentido e a segurança subjetiva necessária para agir. Os sujeitos evocam e justificam suas conquistas ou perdas ao vínculo com o espiritual, com Deus, o que lhes aquieta possíveis sentimentos de autossuficiência ou decepção. A manifestação ao transcendente, então, é associada tanto para aspectos positivos - como fatos considerados inexplicáveis atribuídos à providência divina (como, por exemplo, o recebimento inesperado do pagamento de uma dívida), quanto para aspectos negativos, atribuídos à "ação demoníaca" (no caso da IRC) ou aos sacrifícios, o que leva à santificação.

Adicionalmente, é inerente às categorias "empreendedor apostólico" e "empreendedor de EdC" um conjunto de normas que pressupõe prêmios ou sanções internas e externas (por exemplo, "doar parte do lucro"). Como afirmou Weber $(2004)^{8}$, isso ocorre na medida em que a crença religiosa se mantém viva; e, no caso dos empreendedores religiosos, pelo entusiasmo com que praticam sua religião, parece que, de fato, mantém-se, fazendo com que a ação empreendedora seja facilitada por essas normas que conferem coerência às duas esferas, econômica e religiosa, por meio de um vocabulário único e a partir de critérios de ação.

Em relação a essa questão, é importante mencionar que, desconsiderando as pequenas diferenças de ênfase e vocabulário, ambas as organizações legitimam atitudes que podem coincidir com o comportamento empreendedor abordado no referencial teórico, tais como "aproveitar as oportunidades", "ser perseverante", "não ter medo do desafio", "agir com coragem", "não ser acomodado" e "ter iniciativa". Além disso, elas oferecem o que pode ser denominado "tecnologia religiosa", isto é, um conjunto de normas e técnicas de comportamento e disciplina emocional - legitimado pela religião e adaptável ao contexto dos negócios - por meio das quais se consegue que as ações sejam realizadas (SERAFIM, 2013).

Em razão disso, há duas consequências. A primeira é que há uma influência, na esfera econômica, dos respectivos éthos religiosos das organizações, na medida em que os empreendedores desenvolvem práticas e atuam no mercado utilizando-se de recursos e comportamento baseados na tecnologia religiosa ${ }^{9}$, retificandose, pois, a frase "negócios são negócios, religião à parte". Aliás, no que foi possível apreender dos dados, a esfera religiosa se entrelaça com a econômica de modo a se tornar determinante em alguns aspectos, ilustrando-se em casos como de doação de parte do lucro para as organizações - o que pode, de certa forma, descapitalizar a empresa.

A questão da doação é um bom exemplo. O caráter negativo da descapitalização em termos financeiros contrastou, ao mesmo tempo, com o significado positivo que a situação tem para o empreendedor, segundo os depoimentos dos entrevistados. Foi possível perceber sua evidente disposição e o desejo de aumentar os lucros para ampliar suas doações às respectivas organizações. Essa disposição pode transformar-se em um fator positivo para os negócios devido à busca de eficiência empresarial por motivos religiosos e não "apenas" por motivos econômicos. Nesse sentido, pode haver uma evidência de que a religião possui certo grau de influência na busca de eficiência organizacional (WEBER, 2004).

Tal quadro leva à segunda consequência. Os motivos religiosos, aliados às tecnologias religiosas, proporcionam ao empreendedor sentido e aprendizagem acerca de aspectos comportamentais como o autocontrole, enfrentamento de problemas e relacionamento com as pessoas, ou seja, o contexto (DANJOU, 2002) religioso influencia positivamente a ação empreendedora. Houve relatos de casos em que o empreendedor afirmou que aprendeu com a religião a ter mais equilíbrio emocional e a ter menos ansiedade na vida pessoal e profissional, o que modificou sua maneira de lidar com os assuntos de negócio.

\footnotetext{
${ }^{8}$ Ver a epígrafe no início deste artigo.

9 Enfatiza-se essa característica para contrastar com a afirmação inversa de que há uma inundação da esfera religiosa pela econômica, sendo esta última a abordagem ou conclusão mais comum nos textos acadêmicos.
} 
Outro entrevistado afirmou que aprendeu a se relacionar melhor com as pessoas e a valorizá-las em seu ambiente de trabalho, o que aperfeiçoou sua atuação como empreendedor. Um terceiro revelou, ainda, que a religião lhe proporcionou um objetivo de vida, que conseguiu transpor para seus negócios, o que lhe deu uma "satisfação muito grande". É certo que tal causalidade precisaria ser mais bem investigada, mas, como se trata do sentido que o agente atribui à relação entre sua participação em uma organização religiosa e seu papel como empreendedor, é possível reconhecer indícios importantes de que a religião desenvolve aptidões indispensáveis para a prática empreendedora que podem repercutir em sua conduta econômica racional. Além disso, permite-se afirmar que as práticas religiosas podem desenvolver aptidões diferentes da mera conduta econômica: do ponto de vista da ação econômica são irracionais, mas elas compõem o "espírito empreendedor". A dimensão espiritual, nesse aspecto, vincula-se subjetivamente à prática econômica, transpondo a racionalidade instrumental (RAMOS, 1989) e movendo a ação empreendedora a partir de dimensões como a fé e a esperança (WEBER, 2004; SWEDBERG, 2005).

Em relação à "fé": do ponto de vista schumpeteriano, em determinados momentos de incerteza nos quais não se tem todas as informações necessárias para tomar uma decisão, o empreendedor precisa dar um "salto no escuro", ou seja, sua ação tem de ser realizada sem que ele elabore todos os procedimentos racionais do que há para fazer. Em tal situação, além de não ter informações suficientes, o empreendedor também não conhece todas as consequências da ação, o que limita a ação racional em termos de adequação entre meios e fins. Dessa forma, o êxito de sua ação também pode depender da intuição, o que leva a associar o "salto no escuro" à fé ou à confiança do empreendedor apostólico ou de EdC na providência, assim como atribuir seu êxito nos negócios, diante das incertezas do mercado, ao Espírito Santo ou a "Jesus em meio" palavras, a aptidão desenvolvida de ter fé em momentos de incerteza, imprevisibilidade ou dificuldade, impulsiona-os nesse particular a agirem de modo semelhante ao empreendedor descrito por Schumpeter (1961).

A segunda dimensão a ser reconhecida como elemento associado à ação do empreender no mercado é a "esperança". Da mesma forma que explicitado o "salto no escuro", o empreendedor também é motivado pela esperança de que, agindo segundo a vontade de Deus, tudo vai dar certo, de um jeito ou de outro, mesmo que em um primeiro momento ocorram dificuldades ou prejuízos decorrentes da decisão. No final das contas, ele "espera" que o resultado de suas ações seja "o melhor" porque, além de suas habilidades e conhecimentos, o empreendedor conta com a ação divina (o empreendedor não age apenas "com suas próprias forças"), tanto no discernimento das decisões quanto no encadeamento dos fatos. Dessa forma, a esperança na ação divina e a perspectiva de um horizonte de êxito fazem com que eles suportem consideravelmente, e de uma maneira especial, as possíveis adversidades que uma decisão acarreta.

Em relação aos empreendedores estudados, deve-se comparar, ainda, seus padrões biográficos (DANJOU, 2002). Os empreendedores apostólicos geralmente possuem um histórico de algum problema grave que os fez converter-se à IRC e que os "libertou", como a dependência química (drogas lícitas ou ilícitas), problemas psiquiátricos (como síndrome do pânico), angústias existenciais ou problemas financeiros. Ademais, declararam que a vinculação religiosa melhorou muito sua qualidade de vida em comparação ao período em que não eram convertidos à IRC.

Por sua vez, os empreendedores da EdC não provêm de uma experiência de conversão, mas de uma continuidade de sua trajetória no MF, caracterizada por um histórico de busca ou sensibilidade ao tema da justiça social. Tal característica leva a reconhecer, em termos de diferenciação dos perfis dos empreendedores religiosos que, enquanto o empreendedor apostólico está associado a uma dimensão

\footnotetext{
10 "Jesus em meio" é uma expressão embasada na promessa de Jesus que está em Mateus (18, 20): "Onde dois ou mais estiverem reunidos em meu nome aí estou eu no meio deles". "Trata-se do estabelecimento de relações sociais simétricas orientadas pelo amor, que realizam um perfeito consenso e acordo no grupo em questão", possibilitando tomadas de decisão e resolução de conflitos. "Tal acordo e concórdia, com os consequentes sentimentos de alegria, paz, fraternidade, harmonia compartilhados por todos, são interpretados como sinais externos de uma presença invisível, mas real, de Jesus no grupo" (RIBEIRO, 2003, p. 101).
} 
terapêutica - coerente com a ênfase da "restauração" da IRC - o empreendedor da EdC está associado a uma dimensão de missão, relacionado a seu comprometimento com o desenvolvimento do projeto de EdC.

Um ponto de toque entre esses empreendedores é o forte comprometimento com as respectivas organizações religiosas. É comum participarem intensivamente de atividades eclesiais, ações assistenciais, encontros, palestras e seminários, muitas vezes apenas para prestigiar ou oferecer ajuda na organização desses eventos. Um traço desse comprometimento é a ajuda mútua entre esses empreendedores. Além do fortalecimento dos laços sociais provenientes da coincidência da participação conjunta em grupos que ambas as organizações possuem (como as de ação assistencial, por exemplo), a ajuda mútua ocorre em decorrência da formalização do papel dos empreendedores - por meio da Arepe e da EdC - o que facilita empréstimos de dinheiro, bênção de empresas (no caso da IRC), transferência de tecnologia (no caso da EdC), conversas sobre problemas na empresa, entre outros. A organização religiosa torna-se, então, uma "avalista" informal, no sentido de que as interações entre estranhos ocorridas no interior das organizações se estabelecem a partir de um grau de confiança maior que entre estranhos na maioria das organizações seculares ou na sociedade.

Para finalizar, no âmbito do contexto religioso que envolve o empreendedor, portanto, é possível entender que sua ação está baseada nas informações objetivas de seu ambiente e em suas características biográficas (DANJOU, 2002). Entretanto, há uma dimensão a ser considerada no contexto de atuação do empreendedor religioso, qual seja, a ação empreendedora também é vinculada aos desígnios do transcendente.

\section{Considerações Finais}

Este artigo apresentou uma discussão acerca da relação e a influência da crença religiosa - em sua forma organizacional de igreja - sobre seus empreendedores-membros, enquanto frequentadores da esfera econômica. Essa influência foi considerada, neste trabalho, intencional e objetivada nas categorias "empreendedor apostólico" e "empreendedor da economia de comunhão".

Destacou-se que, tanto para os empreendedores apostólicos como para os de EdC, os espaços de incerteza das circunstâncias do mercado são preenchidos pelo transcendente, que lhes dá sentido e a segurança subjetiva necessária para agir. O sentido é tanto para aspectos positivos quanto para aspectos negativos da realidade social e econômica, e faz com que os empreendedores considerem a performance espiritual diretamente relacionada à performance empresarial.

Também se viu que as organizações religiosas oferecem aos empreendedores o que foi denominado "tecnologia religiosa" que, aliada às motivações religiosas, pode desenvolver aptidões diferentes da mera conduta econômica. Do ponto de vista da ação econômica, as motivações podem ser consideradas irracionais, mas compõem o "espírito" empreendedor, configurado na "fé" e na "esperança". A primeira - a aptidão desenvolvida de ter fé em momentos de incerteza, imprevisibilidade ou dificuldade - os impulsiona nesse particular a agir de modo semelhante ao empreendedor descrito por Schumpeter (1961). A segunda - a esperança na ação divina e em um horizonte de êxito - faz com que eles suportem consideravelmente e de maneira especial as possíveis adversidades que uma decisão acarreta.

Em ambas as experiências econômicas, há um misto de valores e interesses com doses diversas em cada uma delas. Na IRC parece haver a prevalência da racionalidade econômica na orientação de suas ações. Arrisca-se afirmar que parte das adesões se dá por interesses ideais-religiosos e para contribuir com a expansão da igreja na esfera econômica; e a outra parte ocorre por interesses materiais, pela conveniência dos apoios que o adepto poderá receber. $\mathrm{Na} \mathrm{EdC}$, por sua vez, parece haver adesões mais relacionadas à causa que o projeto instiga do que geradas pela conveniência que ele pode proporcionar. Enquanto na IRC a razão de ser da Arepe é o apoio ao empreendedor, a razão de ser da EdC é o empreendedor oferecer apoio aos mais pobres, coerentemente com as normas de conduta do movimento. Em outras palavras, enquanto na IRC o apoio ao empreendedor é o fim, no MF é o meio para a consecução de um projeto econômico mais amplo. 


\section{Referências}

ALDRICH, H. E. Entrepreneurship. In: SMELSER, N. J.; SWEDBERG, R. (Eds.). The handbook of economic sociology. 2. ed. Princeton, NJ: Princeton University Press, 2005. 451-477 p.

ANDION, C.; SERVA, M. A etnografia e os estudos organizacionais. In: GODOI, C. K.; BANDEIRA-DE-MELLO, R.; SILVA, A. B. (Org.). Pesquisa qualitativa em estudos organizacionais: paradigmas, estratégias e métodos. São Paulo: Saraiva, 2006. 207-239 p.

BERGER, P. L. O Dossel Sagrado: Elementos para uma teoria sociológica da religião. São Paulo: Paulus, 2004.

BRUNI, L. Comunhão e as novas palavras em economia. Vargem Grande Paulista, São Paulo: Editora Cidade Nova, 2005.

CARLTON, R. B.; HOFER, C. W.; MEEKS, M. D. The entrepreneur and entrepreneurship: operational definitions of their role in society. 1998. Disponível em: <http://www.saber.uca.edu/research/1998>. Acesso em: 29 mar. 2005.

DANJOU, I. L'entrepreneuriat: um champ ferile à la recherche de son unité. Revue Française de Gestión, v. 28 , n. 138 , p. 109-125, 2002.

FERNANDES, V. A dimensão ambiental em organizações produtivas: uma análise da racionalidade da economia de comunhão (EdC). 183 f. Tese (Doutorado em Engenharia Ambiental) - Programa de Pós-Graduação em Engenharia Ambiental, Universidade Federal de Santa Catarina, Florianópolis, 2007.

FILION, L. J. Empreendedorismo: empreendedores e proprietários-gerentes de pequenos negócios. Revista de Administração, v. 32, n. 2, p. 5-28, 1999.

GONÇALVES, J. C. S.; SERRA, A. R. C.; COSTA, C. E. S. A empresarização do sagrado: um estudo sobre a estruturação de igrejas protestantes brasileiras. Revista Eletrônica de Ciência Administrativa, v. 6, n. 2, p. 1-14, 2007.

GRANOVETTER, M. Ação econômica e estrutura social: o problema da imersão. Revista de Administração de Empresas, v. 6, n. 1, art. 5, jan./jun. 2007.

HISRICH, R. D.; PETERS, M. P. Empreendedorismo. 5. ed. Porto Alegre: Bookman, 2004.

LADAIN, M. C. V.; COSTA, I. A.; SALLES, D. M. R. As práticas de gestão de pessoas nas empresas de economia de comunhão: estudo de caso no Polo Spartaco. Cad. EBAPE.BR, Rio de Janeiro, v. 10, n. 4, p. 858-882, dez. 2012. Disponível em: 〈http://ref.scielo.org/x6wk8r>. Acesso em: 31 maio 2013.

LÓPEZ-RUIZ, O. J. O éthos dos executivos das transnacionais e o espírito do capitalismo. 375 f. Tese (Doutorado em Ciências Sociais) - Instituto de Filosofia e Ciências Humanas, Universidade Estadual de Campinas, Campinas, 2004.

MARIZ, C. Libertação e ética. In: ANTONIAZZI, A. et al. Nem anjos nem demônios: interpretações sociológicas do pentecostalismo. Petrópolis, RJ: Vozes, 1994. 204-224 p.

MARTES, A. C. B. Weber e Schumpeter: a ação econômica do empreendedor. Revista de Economia Política, v. 30, n. 2 (118), p. 254-270, 2010.

MARTINELLI, A. Entrepreneurship and management. In: SMELSER, N. J.; SWEDBERG, R. (Eds.). The handbook of economic sociology. Princeton, NJ: Princeton University Press, 1994. 476-503 p.

MERRIAN, S. Qualitative research and case study applications in education. 2. ed. San Francisco: Jossey-Bass, 1998.

MESQUITA, W. A. B. Em busca da prosperidade: trabalho e empreendedorismo entre neopentecostais. $236 \mathrm{f}$. Tese (Doutorado em Sociologia) - Instituto Universitário de Pesquisas do Rio de Janeiro, Rio de Janeiro, 2003. 
MILLS, C. W. A nova classe média [white collar]. Rio de Janeiro: Zahar, 1969.

MOVIMENTO dos Focolares. Disponível em: <http://www.focolare.org/wpcontent/uploads/2011/01/MovFocolari_Presentazione_PT.pdf>. Acesso em: 15 mar. 2014.

PINTO, M. C. S. A economia de comunhão sob o olhar da teoria dos stakeholders. 452 f. Tese (Doutorado em Administração de Empresas) - Programa de Pós-Graduação em Administração de Empresas, Pontifícia Universidade Católica do Rio de Janeiro, Rio de Janeiro, 2004.

RAMOS, A. G. Administração e estratégia do desenvolvimento: elementos de uma sociologia especial da administração. Rio de Janeiro: Ed. FGV, 1966.

RAMOS, A. G. A nova ciência das organizações. Rio de Janeiro: Ed. FGV, 1989.

RIBEIRO, S. F. Carisma e modernidade. Ginetta Calliari, "a ética da unidade e o espírito da economia de comunhão". 356 f. Dissertação (Mestrado em Sociologia) - Faculdade de Filosofia, Letras e Ciências Humanas, Universidade de São Paulo, São Paulo, 2003.

SCHUMPETER, J. A. Teoria do desenvolvimento econômico. Rio de Janeiro: Fundo de Cultura, 1961. 81-129 p.

SERAFIM, M. C. Economia de comunhão como expressão de uma economia plural de origem religiosa. Revista de Economia de Comunhão, n. 3, p. 76-99, 2013.

SERAFIM, M. C.; MARTES, A. C. B. Sobre esta pedra edificarei a minha empresa: Organizações religiosas e o incentivo ao empreendedorismo. In: ENCONTRO DA ASSOCIAÇÃO NACIONAL DOS PROGRAMAS DE PÓSGRADUAÇÃO E PESQUISA EM ADMINISTRAÇÃO, 31., 23-26 set. 2007, Rio de Janeiro. Anais... Rio de Janeiro: Anpad, 2007.

SERAFIM, M. C.; MARTES, A. C. B.; RODRIGUEZ, C. L. Segurando na mão de Deus: Organizações religiosas e apoio ao empreendedorismo. Revista de Administração de Empresas, v. 52, n. 2, p. 217-231, mar./abr. 2012.

SIEPIERSKI, C. T. "De bem com a vida": o sagrado num mundo em transformação. 226 f. Tese (Doutorado em Antropologia Social) - Faculdade de Filosofia, Letras e Ciências Humanas, Universidade de São Paulo, São Paulo, 2001 .

SIEPIERSKI, C. T. Fé, marketing e espetáculo: a dimensão organizacional da Igreja Renascer em Cristo. Civitas, v. 3 , n. 1, p. 127-146, 2003.

SWEDBERG, R. Max Weber e a ideia de sociologia econômica. Rio de Janeiro/São Paulo: Ed. UFRJ/Beca Produções Culturais, 2005.

THORNTON, P. H. The sociology of entrepreneurship. Annual Review of Sociology, v. 25, p. 19-46, 1999.

WEBER. M. Economia e sociedade. Brasília, DF: Ed. UnB, 1999. v. 1.

WEBER, M. A ética protestante e o “espírito” do capitalismo. São Paulo: Companhia das Letras, 2004.

WHYTE JR., W. H. The organization man. New York: Simon \& Schuster, 1956.

WUTHNOW, R. New directions in the study of religion and economic life. In: SMELSER, N. J.; SWEDBERG, R. (Eds.). The handbook of economic sociology. 2. ed. Princeton, NJ: Princeton University Press, 2005. 603-626 p.

YIN, R. K. Case study research. Newbury Park, CA: Sage, 1984. 